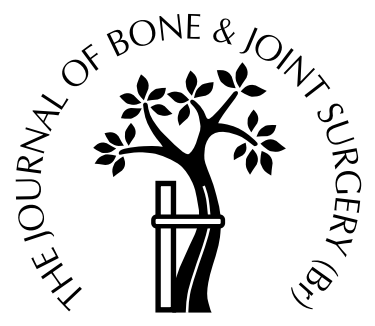

\title{
Open treatment of anterior impingement of the ankle
}

\author{
R. Coull, T. Raffiq, L. E. James, M. M. Stephens \\ From the Cappagh National Orthopaedic Hospital, Dublin, Ireland
}

$\mathbf{W}$ e assessed the long-term outcome of open debridement for the treatment of anterior impingement of the ankle in 27 patients. By using preoperative radiographs to group patients according to both the McDermott and the van Dijk scoring system, we assessed the accuracy of these classifications in predicting outcome. The Ogilvie-Harris scoring system, a visual analogue scale of patient satisfaction, the time to return to full activities, and the ability to return to sports determined the clinical outcome. Follow-up radiographs were used to assess the recurrence of osteophytes. We also assessed the incidence of talar osteochondral lesions at surgery.

At a mean follow-up of 7.3 years, 23 of 25 patients $(92 \%)$ without joint-space narrowing had a good or excellent result. Improvement in the Ogilvie-Harris score was seen in all patients. In athletes, 19 of $24(79 \%)$ were able to return to sports at the same level. Two patients with preoperative joint-space narrowing had a poor result.

Osteophytes usually recurred and most patients did not feel that the range of dorsiflexion returned to normal, but symptomatic relief allowed most to return to high-level sport.

Our results for non-arthritic joints suggest that this is a safe and successful procedure.

J Bone Joint Surg [Br] 2003;85-B:550-3.

Received 23 September 2002; Accepted 29 October 2002

R. Coull, FRCS (Trauma \& Orth), Specialist Registrar

T. Raffiq, FRCS I, Senior House Officer

M. M. Stephens, MSc BioEng, FRCS I, Consultant Orthopaedic Surgeon Cappagh National Orthopaedic Hospital, Finglas, Dublin II, Republic of Ireland.

L. E. James, MRCS, Clinical Research Fellow

University College Hospital, Grafton Way, London WC1E 3BG, UK.

Correspondence should be sent to Mr M. M. Stephens at Suite 8, Mater Private Hospital, Eccles Street, Dublin 7, Republic of Ireland.

(C)2003 British Editorial Society of Bone and Joint Surgery doi:10.1302/0301-620X.85B4.13871 \$2.00

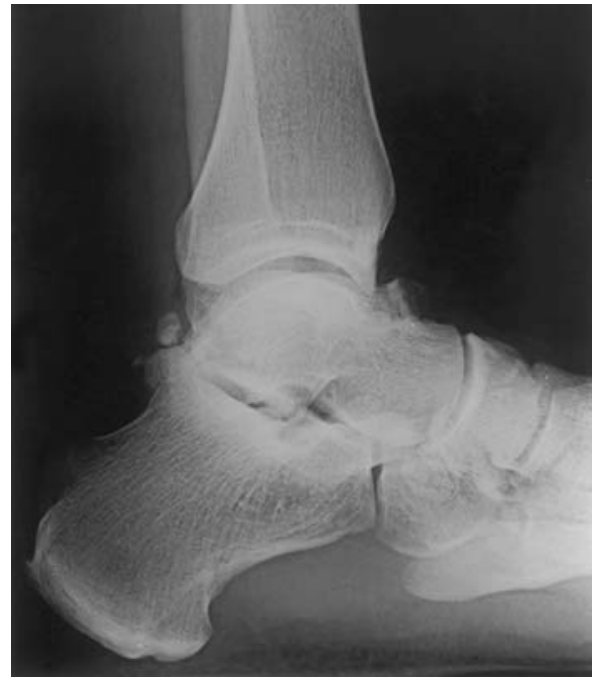

Fig. 1

Radiograph showing anterior impingement spur of the tibia with the talar spur (McDermott grade 3).

Anterior impingement is a common cause of pain in the ankle especially in sportsmen. The primary symptom is anterior pain on dorsiflexion. The condition, first described by Morris ${ }^{1}$ and termed 'footballers' ankle' by McMurray, ${ }^{2}$ is common in sports involving forced dorsiflexion of the ankle. Although the aetiology of the impingement lesion has not been clearly elucidated, the suspected mechanism is recurrent microtrauma from forced dorsiflexion leading to haemorrhage, scarring and the formation of new bone in the form of spurs at the anterior aspect of the ankle. ${ }^{3}$ Once formed, forced dorsiflexion of the ankle causes impingement between the spur and the neck of the talus (Fig. 1). Spurs may also occur in the recess of the talar neck and were formerly assumed to be reciprocating 'kissing' lesions, but they usually do not overlap with the tibial spurs. ${ }^{4}$

Impingement lesions are more common in athletes, but many are asymptomatic requiring no treatment. ${ }^{5,6}$ The diagnosis of symptomatic lesions is made clinically and confirmed radiologically. A bony spur or osteophyte is seen on a lateral radiograph of the ankle.

Successful open treatment of anterior impingement lesions has previously been reported, ${ }^{7-10}$ but there are no large series 
Table I. The Ogilvie-Harris scoring system for anterior impingement

\begin{tabular}{|c|c|c|c|c|}
\hline & $\begin{array}{l}\text { Poor } \\
\text { (1) }\end{array}$ & $\begin{array}{l}\text { Fair } \\
(2)\end{array}$ & $\begin{array}{l}\text { Good } \\
\text { (3) }\end{array}$ & $\begin{array}{l}\text { Excellent } \\
\text { (4) }\end{array}$ \\
\hline Pain & Severe & Moderate & Mild & None \\
\hline Swelling & Moderate/severe & $\begin{array}{l}\text { Mild with activities of } \\
\text { daily living }\end{array}$ & With exercise & None \\
\hline Stiffness & Minimal movement & Painful deficit & Slight & None \\
\hline Activity & Limited & Moderate limits & Minor limits & No limits \\
\hline
\end{tabular}

Table II. The results of open debridement of 27 anterior impingement lesions according to the McDermott classification grade

\begin{tabular}{|c|c|c|c|c|c|c|c|}
\hline \multirow[b]{2}{*}{ McDermott grade } & \multirow[b]{2}{*}{ Number } & \multirow[b]{2}{*}{ Results } & \multicolumn{2}{|c|}{ Ogilvie-Harris score } & \multirow{2}{*}{$\begin{array}{l}\text { Mean time to return } \\
\text { to full activities (wks) }\end{array}$} & \multirow{2}{*}{$\begin{array}{l}\text { Able to play sport } \\
\text { at same level } \\
\text { (if applicable) }\end{array}$} & \multirow{2}{*}{$\begin{array}{l}\text { Satisfaction with } \\
\text { result }(>\mathbf{8 0} \% \\
\text { satisfied) }\end{array}$} \\
\hline & & & Preoperatively & At follow-up & & & \\
\hline \multirow[t]{3}{*}{1} & 12 & Excellent & & 7 & & & \\
\hline & & Good & 1 & 5 & 14.25 & 8 of 11 & 9 of 12 \\
\hline & & Unsatisfactory & 11 & & & & \\
\hline \multirow[t]{3}{*}{2} & 9 & Excellent & & 5 & & & \\
\hline & & Good & & 2 & 12.7 & 6 of 8 & 9 of 9 \\
\hline & & Unsatisfactory & 9 & 2 & & & \\
\hline \multirow[t]{3}{*}{3} & 4 & Excellent & & 1 & & & 2 of 4 \\
\hline & & Good & & 3 & 17.0 & 4 of 4 & \\
\hline & & Unsatisfactory & 4 & & & & \\
\hline \multirow[t]{3}{*}{1 to 3 combined } & 25 & Excellent & & 13 & & & \\
\hline & & Good & 1 & 8 & 14.0 & 18 of 23 & 20 of 24 \\
\hline & & Unsatisfactory & 24 & 2 & & & \\
\hline \multirow[t]{3}{*}{4} & 2 & Excellent & & & & & \\
\hline & & Good & & & 7.0 & 0 of 1 & 0 of 2 \\
\hline & & Unsatisfactory & 2 & 2 & & & \\
\hline \multirow[t]{3}{*}{ Overall } & 27 & Excellent & & 13 & & & \\
\hline & & Good & 1 & 8 & 13.0 & 18 of 24 & 20 of 26 \\
\hline & & Unsatisfactory & 26 & 4 & & & \\
\hline
\end{tabular}

assessing the long-term follow-up results. Most report the results of arthroscopic treatment, reflecting the rapidly expanding interest in arthroscopic surgery. ${ }^{3,11-14}$ Tol et $\mathrm{al}^{3}$ recently showed good and excellent results in $77 \%$ of patients at a minimum follow-up of five years after arthroscopic excision of bony impingement lesions in 30 non-arthritic ankles.

Our aim was to report the long-term results of open excision of impingement lesions.

\section{Patients and Methods}

We identified 29 patients who had undergone debridement of an anterior impingement lesion between 1991 and 1996. Two were lost to follow-up leaving 27 in the study. There were six women and 21 men with a mean age at surgery of 28 years (19 to 46$)$. The mean follow-up was 7.3 years $(5.0$ to 9.3). They had a clinical and radiological assessment and we retrieved the preoperative weight-bearing radiographs for each. All patients had had a period of conservative treatment which failed, including physiotherapy, intra-articular injections of steroids and the use of a heel raise.

The senior author (MMS) carried out all the operations. Before open debridement each patient had an arthroscopy of the ankle to determine the presence of an osteochondral talar lesion and the site of the impingement lesion on the anterior tibial plafond, i.e. anteromedial or anterolateral. Following either a $5 \mathrm{~cm}$ anteromedial or anterolateral inci- sion, bony and soft-tissue impingement lesions were excised with small straight osteotomes and by sharp dissection. The tibial spur has a fibrocartilaginous articular surface. Resection of the spur exposes normal hyaline articular cartilage known as the "coconut-meat' sign. ${ }^{15}$ Treatment of talar lesions was by excision and drilling of the subchondral bone or by internal fixation of the osteochondral fragment. After operation, all patients wore a walking cast for four weeks before movement was allowed.

Clinical assessment consisted of subjective and functional assessment using the Ogilvie-Harris scoring system ${ }^{10}$ which includes measurement of pain, swelling, stiffness and limitation of activity with a maximum score of 16 points (Table I). The results were scored as excellent (15 to 16 points), good (13 to 14$)$ or unsatisfactory $(<13)$. Other variables used for evaluation included determination of patient satisfaction using a visual analogue scale, the time to postoperative return to full activity, and ability to return to sport.

Radiological assessment was by comparing the preoperative lateral standing radiograph with the up-to-date film. The senior author (MMS) graded all the radiographs in a blinded fashion using classification systems described by Scranton and McDermott ${ }^{14}$ and Tol et al. ${ }^{3}$ The McDermott grading categorises impingement lesions into grades 1 to $4 .{ }^{14} \mathrm{~A}$ tibial spur of less than $3 \mathrm{~mm}$ is grade 1 and greater than 3 $\mathrm{mm}$ is grade 2 . In grade 3 the spur is significant, with or without fragmentation, and there is a secondary spur on the 
dorsum of the talus. In grade 4 there is pantalocrural arthritic destruction. The van Dijk grading classifies impingement lesions into grades 0 to II. In grade $\mathrm{O}$ there is soft-tissue impingement alone without the formation of a bony spur. In grade I there is the formation of a spur of any size without joint-space narrowing, and in grade II the arthritis is accompanied by anterior spurs. ${ }^{3}$

For statistical analysis we used stata version 7.0 (TEXAS). The Wilcoxon rank-sum test determined any differences between preoperative and postoperative OgilvieHarris scores. The Kruskal-Wallis test established any differences in Ogilvie-Harris scores across McDermott grades. Fisher's exact test was used to determine differences across McDermott grades in the ability to return to sport.

\section{Results}

We analysed the results according to the McDermott grading of the preoperative radiographs (Table II). The van Dijk classification did not prove to be useful for grouping the patients; no patients had grade-O changes, 25 had grade-I changes, and two had grade-II changes. The two patients with grade-II changes corresponded to the two patients in McDermott grade 4. These patients had established osteoarthritis of the ankle.

There was a significant difference between pre- and postoperative Ogilvie-Harris scores for the whole group ( $\mathrm{p}=$ $0.00005)$. For the 25 patients with McDermott grades 1 to 3, 13 had excellent, 10 good and two unsatisfactory results. Across grades 1 to 3 there was no significant difference in improvement in the Ogilvie-Harris score at follow-up ( $1 v 2$ $\mathrm{p}=0.43 ; 1 \vee 3 \mathrm{p}=0.54,2 \vee 3 \mathrm{p}=0.12)$. Also there was no significant difference in the ability to return to sport at the same level across McDermott groups $(1 v 2 \mathrm{p}=0.6,1 v 3 \mathrm{p}$ $=0.36,2 v 3 \mathrm{p}=0.46$ ).

At follow-up 14 of 25 patients (56\%) with McDermott grades 1 to 3 complained of at least mild residual stiffness in the ankle. There were two unsatisfactory results in the McDermott grade-2 patients. In both of these the OgilvieHarris score improved from 7 preoperatively to 11 at follow-up. One patient was $85 \%$ satisfied with the result on the visual analogue scale but complained of persistent stiffness in the ankle. The second was $80 \%$ satisfied on the visual analogue scale but had been unable to return to playing soccer because of pain.

The mean time to return to full activities including sport was 13 weeks (6 to 41). Of 23 patients with McDermott grades 1 to 3 who played regular sport, 18 (78\%) were able to return to sport at the same level.

On visual analogue assessment, 20 of 25 patients (80\%) with McDermott grades 1 to 3 were at least $80 \%$ satisfied with their outcome. Mild residual stiffness and inability to return to sport were the commonest reasons cited for patients who were less than $100 \%$ satisfied.

Talar lesions occurred in six patients with McDermott grades 1 and 2 . Five were treated by excision of the osteo- chondral lesion and drilling of the subchondral bone to encourage the formation of fibrocartilage. The other patient underwent internal fixation of the osteochondral fragment with a Herbert screw. In the subgroup there were five excellent and one good result.

None of the patients with McDermott grades 1 to 3 developed narrowing of the joint space of the ankle. Bony spurs had recurred in all patients at follow-up.

Two patients required reoperation after failure to improve following the initial procedure. After the second procedure one patient had an excellent and one a good result.

\section{Discussion}

The long-term outcome after open treatment of anterior impingement of the ankle has not previously been reported. Our study showed that $92 \%$ of patients without preoperative arthritis had a satisfactory outcome. This result compares favourably with the long-term results of arthroscopic treatment reported by Tol et $\mathrm{al}^{3}$ who found good and excellent results in $77 \%$ of patients with bony spurs and no arthritis. Open surgery therefore remains the procedure of choice against which arthroscopic surgery should be evaluated.

The main advantage of the arthroscopic technique is a more rapid return to full activities. Scranton and McDermott ${ }^{14}$ found a significantly reduced recovery period in patients treated arthroscopically (mean six weeks) compared with those treated with arthrotomy (mean eight weeks). The time to return to full activities was 13 weeks in our study. After arthrotomy we recommend that a cast be worn to allow capsular healing. Since this study we have reduced this period from four to two weeks.

None of the patients in McDermott grades 1 to 3 developed arthritic changes over time (i.e. progressed to McDermott grade 4 or van Dijk grade II). This lends further weight to the conclusion that this is not an arthritic or prearthritic condition. Both patients with preoperative arthritis had poor results confirming the conclusion from previous studies that this is not a successful procedure for arthritic ankles in the long term. $3,11,14,16$

We were unable to find significant differences in outcome between McDermott groups. This contrasts with the results of previous arthroscopic studies in which better results were achieved for McDermott grade-1 ankles, suggesting that arthroscopic debridement should be reserved for this group of patients. ${ }^{11,14}$

There were only four patients with McDermott grade 3; one had an excellent and three had good results. Statistical analysis of this small subgroup should be interpreted with caution.

We found that the spurs recurred in all patients at a mean follow-up of 7.3 years. Tol et $\mathrm{al}^{3}$ noted that two-thirds of patients had recurrent spurs at a mean of 6.5 years. The reason why these recurrent spurs did not become more 
symptomatic is not obvious, but $56 \%$ of patients did complain of residual stiffness. Patients returning to high-level sports are subjecting their ankles to the same microtrauma as before surgery and therefore the recurrence of spurs is not surprising.

The presence of a talar lesion did not effect the clinical result. The incidence of talar lesions $(22 \%)$ in anterior ankle impingement has not been previously described.

The Ogilvie-Harris scoring system modified from McGuire et $\mathrm{al}^{17}$ has been validated in previous studies. ${ }^{10,11,16}$ Our use of retrospectively assessed preoperative Ogilvie-Harris scores is a potential weakness in our method of data collection.

At long-term follow-up open debridement for anterior impingement of the ankle has been shown to be an effective form of treatment. Future studies of arthroscopic treatment must match these results before such treatment is deemed to be superior.

No benefits in any form have been received or will be received from a commercial party related directly or indirectly to the subject of this article.

\section{References}

1. Morris LH. Athlete's ankle. J Bone Joint Surg 1943;25:220.

2. McMurray TP. Footballer's ankle. J Bone Joint Surg [Br] 1950;32B:68-9.

3. Tol JL, Verheyen CPPM, van Dijk CN. Arthroscopic treatment of anterior impingement in the ankle. J Bone Joint Surg [Br] 2001;83-B:9-13.
4. Berberian WS, Hecht PJ, Wapner KL, DiVerniero R. Morphology of tibiotalar osteophytes in anterior ankle impingement. Foot Ankle Int 2001;22:313-7.

5. O'Donoghue DH. Impingement exostoses of the talus and tibia. J Bone Joint Surg [Am] 1957;39-A:835-52.

6. King JW, Tullos H, Stanley R, Fain R, Brelsford HJ. Lesions of the feet in athletes. South Med J 1971;64:45-58.

7. Brodelius A. Osteoarthritis of the talar joints in footballers and ballet dancers. Acta Orthop Scand 1960;30:309-14.

8. Parkes JC, Hamilton WG, Patterson AH. The anterior impingement syndrome and the ankle. J Trauma 1980;20:895-8.

9. Hensley JP, Saltrick K, Le T. Anterior ankle arthroplasty: a retrospective study. J Foot Surg 1990;29:169-72.

10. Ogilvie-Harris DJ, Mahomed N, Demaziére A. Anterior impingement of the ankle treated by arthroscopic removal of bony spurs. J Bone Joint Surg [Br] 1993;75-B:437-40.

11. Branca A, Di Palma L, Bucca C, Visconti CS, Di Mille M. Arthroscopic treatment of anterior ankle impingement. Foot Ankle Int 1997; 18:418-23.

12. Liu SH, Raskin A, Osti L, et al. Arthroscopic treatment of anterolateral ankle impingement. Arthroscopy 1994;10:215-8.

13. Reynaert P, Gelen G, Geens G. Arthroscopic treatment of anterior impingement of the ankle. Acta Orthop Belg 1994;60:384-8.

14. Scranton PE, McDermott JE. Anterior tibiotalar spurs: a comparison of open versus arthroscopic debridement. Foot Ankle 1992;13:125-9.

15. Stephens MM, Murphy PG. Surgical treatment of anterior and posterior impingement of the ankle. In: Wülker N, Stephens MM, Cracchiolo A III, eds. An atlas of foot and ankle surgery. Martin Dunitz. London: 1998:301-5

16. van Dijk CN, Tol JL, Verheyen CC. A prospective study of prognostic factors concerning the outcome of arthroscopic surgery for anterior ankle impingement. Am J Sports Med 1997;25:737-45.

17. McGuire MR, Kyle RF, Gustillo RB, Premer RF. Comparative analysis of the ankle arthroprosthesis versus ankle arthrodesis. Clin Orthop 1988;226:174-81. 